\title{
MASM, a Matrine Derivative, Offers Radioprotection by Modulating Lethal Total-Body Irradiation-Induced Multiple Signaling Pathways in Wistar Rats
}

\author{
Jianzhong $\mathrm{Li}^{1}{ }^{1, *}$, Jing $\mathrm{Xu}{ }^{1,2}$, Yiming $\mathrm{Lu}^{1}{ }^{1}$, Lei Qiu ${ }^{1}$, Weiheng $\mathrm{Xu}{ }^{1}$, Bin $\mathrm{Lu}^{1}$, Zhenlin $\mathrm{Hu}^{1}{ }^{1}$, \\ Zhiyong Chu ${ }^{3}$, Yifeng Chai ${ }^{1}$ and Junping Zhang ${ }^{1, *}$ \\ 1 School of Pharmacy, Second Military Medical University, Shanghai 200433, China; \\ xujing0601103@live.cn (J.X.); bluesluyi@163.com (Y.L.); qlcong021@163.com (L.Q.); \\ xuweiheng7114@163.com (W.X.); binlu@smmu.edu.cn (B.L.); zhenlinhu@hotmail.com (Z.H.); \\ yfchai@smmu.edu.cn (Y.C.) \\ 2 Department of Pharmacy, East Hospital, Dongji University, Shanghai 200085, China \\ 3 The Naval Medical Research Institute, Shanghai 200433, China; zhiyongchu@tom.com \\ * Correspondence: lijianzhong1234@hotmail.com (J.L.); jpzhang08@hotmail.com (J.Z.); \\ Tel.: +86-21-8187-1331 (J.L.); +86-21-8187-1328 (J.Z.) \\ Academic Editor: Derek J. McPhee \\ Received: 17 March 2016; Accepted: 6 May 2016; Published: 17 May 2016
}

\begin{abstract}
Matrine is an alkaloid extracted from Sophora flavescens Ait and has many biological activities, such as anti-inflammatory, antitumor, anti-fibrosis, and immunosuppressive properties. In our previous studies, the matrine derivative MASM was synthesized and exhibited potent inhibitory activity against liver fibrosis. In this study, we mainly investigated its protection against lethal total-body irradiation (TBI) in rats. Administration of MASM reduced the radiation sickness characteristics and increased the 30-day survival of rats before or after lethal TBI. Ultrastructural observation illustrated that pretreatment of rats with MASM significantly attenuated the TBI-induced morphological changes in the different organs of irradiated rats. Gene expression profiles revealed that pretreatment with MASM had a dramatic effect on gene expression changes caused by TBI. Pretreatment with MASM prevented differential expression of 53\% (765 genes) of 1445 differentially expressed genes induced by TBI. Pathway enrichment analysis indicated that these genes were mainly involved in a total of 21 pathways, such as metabolic pathways, pathways in cancer, and mitogen-activated protein kinase (MAPK) pathways. Our data indicated that pretreatment of rats with MASM modulated these pathways induced by TBI, suggesting that the pretreatment with MASM might provide the protective effects on lethal TBI mainly or partially through the modulation of these pathways, such as multiple MAPK pathways. Therefore, MASM has the potential to be used as an effective therapeutic or radioprotective agent to minimize irradiation damages and in combination with radiotherapy to improve the efficacy of cancer therapy.
\end{abstract}

Keywords: MASM; radiation lethality; total-body irradiation; radioprotection; gene expression; MAPK pathways

\section{Introduction}

Radiation source is a kind of physical stress that humans risk in nuclear pollution, space flight and radiation therapy for cancer events [1-3]. Radiation exposure increases the oxidative pressure and induces further damages such as DNA lesions, cell death, cancer and other diseases. Radioprotective agents are administered either before or after radiation exposure to minimize radiation toxicity. Several compounds have been reported to offer potential for radiation protection, but most of them are not suitable for clinical application due to their toxicity and poor specificity [4-6]. This warrants 
development of suitable radioprotective agents with minimum toxicity that can be used under occupational as well as clinical conditions.

Matrine (molecular formula: $\mathrm{C}_{15} \mathrm{H}_{24} \mathrm{~N}_{2} \mathrm{O}$ ) is an alkaloid found in the herb root of a traditional Chinese medicine, Sophora flavescens Ait [7,8]. It has a variety of pharmacological effects and has been wildly used in clinical practice in China for the treatment of viral hepatitis, liver fibrosis, heart arrhythmia and skin inflammation without any obvious side effects [7-13]. In addition, many studies have shown that matrine possesses strong antitumor activities in vitro and in vivo $[8,14]$. Matrine and its compounds also have been extensively used alone or in combination with chemotherapy or radiotherapy for many years in China [14]. Clinical studies have shown that matrine and its compounds attenuate the side effects of chemotherapy and radiotherapy by improving the life quality and regulating the immunologic function of patients with cancer, as well as synergizing the therapeutic effects of chemotherapy and radiotherapy [14-18]. In our previous studies, the matrine derivative MASM ((6aS,10S,11aR,11bR,11cS)-10-methylamino-dodecahydro-3a,7a-diazabenzo(de)anthracene-8-thione) was synthesized via classical Michael addition and exhibited potent antiinflammatory and inhibitory activity against liver fibrosis in vitro and in vivo associated with the reduction of Akt phosphorylation $[19,20]$. In this study, we mainly investigate its protection against lethal TBI in Wistar rats.

\section{Results and Discussion}

\subsection{Effect of MASM on 30 Day Survival}

The radiation control group exhibited typical signs of radiation sickness such as reduced intake of food and water, irritability, lethargy, weight loss, ruffling of hair, diarrhea, emaciation and epilation with median survival of only 8 days and $100 \%$ mortality within 10 days (Figure $1 \mathrm{~A})$. MASM $(30 \mathrm{mg} / \mathrm{kg}$ ) alone did not induce any noticeable sign of toxicity within 30 days. On the other hand, rats that were administered with different graded concentrations of MASM once a day for three consecutive days prior to the exposure of lethal TBI (6 Gy) had reduced signs of radiation sickness and improved survival rates. Different concentrations of MASM were found to offer same protection to rats against radiation induced toxic effects by increasing the median survival period to 11 days. Pre-administration of 3,10 and $30 \mathrm{mg} / \mathrm{kg}$ MASM reduced the radiation sickness characteristics, while increasing the 30 -day survival of the irradiated rats by $9 \%, 9 \%$ and $18 \%$ respectively (Figure 1A). The log rank test indicated that the survival curves were significantly different $\left({ }^{* *} p<0.01\right)$. However, when rats were exposed to a lethal dose of 7 Gy TBI, $3 \mathrm{mg} / \mathrm{kg}$ and $10 \mathrm{mg} / \mathrm{kg}$ MASM failed to show increase 30-day survival (Figure 1B). In additional, the log rank test indicated that the survival curves were non-significantly different.

Encouraged by the above results, the therapeutic ability of MASM was also evaluated by administering it $30 \mathrm{~min}$ after exposure to a lethal dose (6 Gy) of TBI. Rats that were administered with different concentrations of MASM once each day for three consecutive days after TBI had reduced signs of radiation sickness and increased median survival (Figure 1C). Administration of MASM $10 \mathrm{mg} / \mathrm{kg}$ and $30 \mathrm{mg} / \mathrm{kg}$ increased the 30 day-survival of the irradiated mice by $9 \%$ and $18 \%$ respectively, confirming its therapeutic ability (Figure 1C). The log rank test indicated that the survival curves were significantly different $\left({ }^{* *} p<0.01\right)$. 

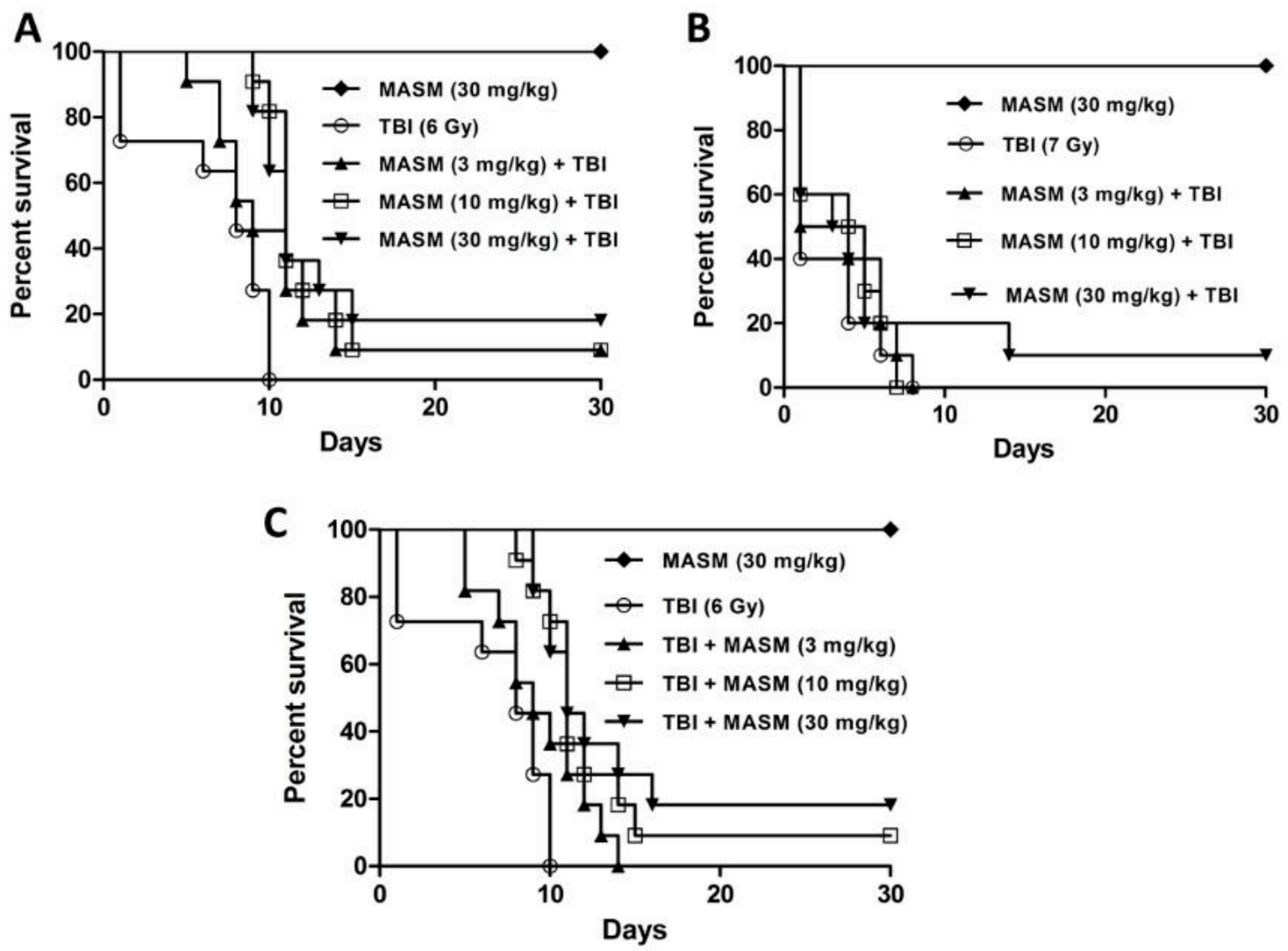

Figure 1. Comparison of survival curves by using Kaplan-Meier method. (A) 30 days survival of rats ( $n=11$ per group) pretreated with MASM $(3 \mathrm{mg} / \mathrm{kg}, 10 \mathrm{mg} / \mathrm{kg}$ and $30 \mathrm{mg} / \mathrm{kg}$ ) once each day for three consecutive days before exposure to 6 Gy TBI. The survival curves were significantly different as predicted by log rank test ( $p=0.0011)$; (B) $30 \mathrm{~d}$ survival of rats $(n=11$ per group) pretreated with MASM $(3 \mathrm{mg} / \mathrm{kg}, 10 \mathrm{mg} / \mathrm{kg}$ and $30 \mathrm{mg} / \mathrm{kg}$ ) once each day for three consecutive days before exposure to 7 Gy TBI; (C) 30 days survival of rats ( $n=11$ per group) treated with MASM $(3 \mathrm{mg} / \mathrm{kg}, 10 \mathrm{mg} / \mathrm{kg}$ and $30 \mathrm{mg} / \mathrm{kg}$ ) once each day for three consecutive days $30 \mathrm{~min}$ after exposure to 6 Gy TBI. The survival curves were significantly different as predicted by log rank test $(p=0.0015)$.

\subsection{Effect of MASM on Radiation-Induced Tissues Injury Using Transmission Electron Microscopy}

To observe the possible protective effect of MASM on radiation-induced tissues injury in rats, transmission electron microscopy was performed. Rats ( $n=10 \mathrm{rats} /$ group) received $30 \mathrm{mg} / \mathrm{kg} / \mathrm{day}$ MASM or water once each day for three days prior to radiation. Significant pathological changes occurred at 1 day after lethal TBI (6 Gy).

Damages in thymus, spleen, liver, small intestine, testis, hippocampus and cortex such as cytoplasmic vacuolization, dilatation of the endoplasmic reticulum and destruction of mitochondria, as well as damages to the cellular membrane, were observed (Figure 2B1-7). In addition, the morphological signs of apoptosis were frequently detected in the splenocytes. Apoptotic splenocytes showed the marginal condensation of chromatin onto the nuclear lamina (Figure 2B2). Vacuoles and mitochondrial swelling were decreased by MASM in the different organs (Figure 2C1-7). Cell apoptosis also significantly attenuated by MASM in the spleen (Figure 2C2). These results illustrated that pretreatment of rats with MASM before exposure to acute lethal TBI significantly attenuated the radiation-induced morphological changes in the irradiated different organs, confirming the protective effects of MASM against radiation-induced tissue injury. 


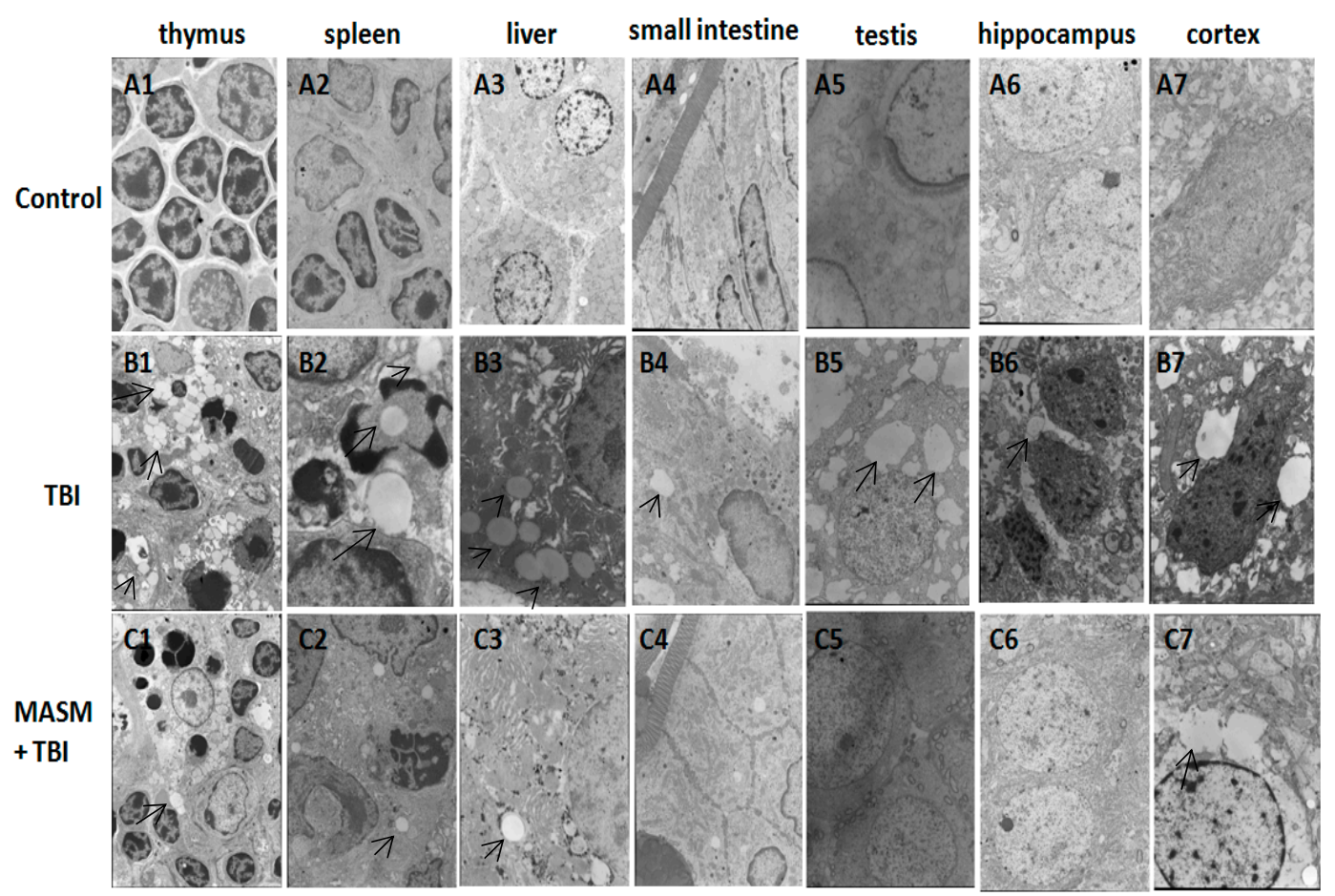

Figure 2. Effect of MASM on radiation-induced tissues injury at 1 day after exposure to lethal TBI (6 Gy) using transmission electron microscopy. (A1-7) Representative photographs of non-irradiated rats; (B1-7) Representative photographs of 10 TBI rats. Cell swelling and large amounts of cytoplasmic vacuoles were observed in the different tissues at 1 day after exposure to lethal TBI (6 Gy); (C1-7) Representative photographs of 10 irradiated rats pretreated with MASM $(30 \mathrm{mg} / \mathrm{kg})$ once each day for three consecutive days before exposure to 6 Gy TBI. MASM pretreatment attenuated the radiation-induced tissues injury such as cytoplasmic vacuoles (arrows). (uranyl acetate and lead citrate staining, $3000 \times)$.

\subsection{MASM Prevents TBI-Induced Differential Expression of Many Genes}

The liver was considered to be a radiosensitive organ [21]. Vacuoles and mitochondrial swelling were significantly decreased by MASM in the liver (Figure 2C3), indicating that MASM ameliorated TBI-induced liver tissues injury. To further investigate the potential molecular basis of the protective effects of MASM on irradiation damage, gene expression analysis was conducted on rats liver tissues using microarrays.

A heatmap was generated (Figure 3) representing 3912 transcripts (probesets) comparing significantly differentially regulated genes $(p<0.01)$ for the treatment groups (TBI, MASM + TBI) versus untreated controls by using one-way analysis of variance (one-way ANOVA) (Supplementary File 1). Cluster analysis of the microarray results revealed that three or four rats from the same group were the closest, indicating that all the experimental data in this study were reliable.

A combined algorithm with simple $t$-test and fold change was used to find differentially expressed genes. By a threshold of $p<0.05$ and absolute fold change (FC) $>1.5,2920$ significant expressed probes were selected by comparison between radiation and wild-type (control) samples, involving 1445 unique genes (Supplementary File 2). Among the genes originally displaying FC $>1.5,414$ were subsequently down-regulated and 1031 up-regulated. In the pretreatment with $30 \mathrm{mg} / \mathrm{kg}$ MASM groups, only 680 out of 1445 genes were still differentially expressed in response to TBI. These results indicated that the treatment with MASM prevented TBI-induced differential expression of $53 \%$ (765 genes) of genes (Supplementary File 3). We focused on these genes for which TBI-induced alteration of expression were abolished or attenuated by MASM pretreatment, as these genes might be regulated by MASM and involved in the protective effects on radiation. 


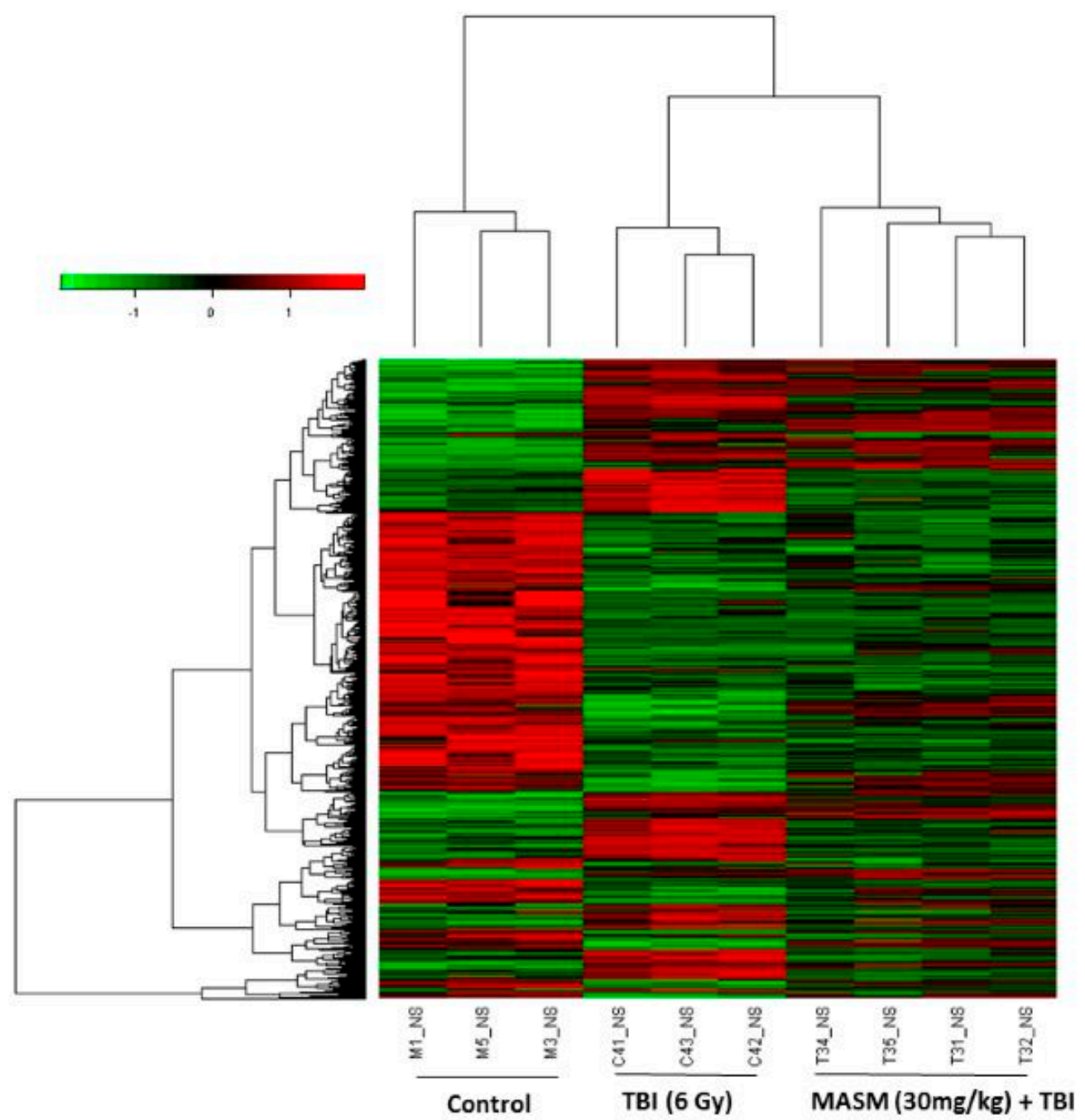

Figure 3. Cluster analysis of individual rats according to the profile of gene expression examined. Genes are organized by hierarchical clustering based on overall similarity in expression patterns. Red represents relative expression greater than the median expression level across all samples, and green represents an expression level lower than the median. Black indicates intermediate expression. Rats from the same treatment group (6 Gy TBI, $30 \mathrm{mg} / \mathrm{kg}$ MASM + 6 Gy TBI) were the closest.

Gene ontology (GO) analysis was then applied to these genes in terms of molecular function, cellular component and biological process. Eleven enriched terms associated with these genes list were identified (Table 1). The identified terms in molecular function were transporter activity, and chemorepellent activity. Only synapse part was in cell component. The terms included in biology process were death, growth, multicellular organismal process, locomotion, rhythmic process, response to stimulus, and localization.

Pathway enrichment analysis indicated that these genes were mainly involved in a total of 21 pathways (Table 2). Most of these pathways were reported to be induced by radiation in the previous studies, such as olfactory transduction [22], cytokine-cytokine receptor interaction [22], neuroactive ligand-receptor interaction [23], pathways in cancer [24-26], MAPK signaling pathway [27], PPAR signaling pathway [28], GnRH signaling pathway [29], calcium signaling pathway [25], acute myeloid leukemia [30,31], vascular smooth muscle contraction [32], gap junction [33], bladder cancer [34,35] and circadian rhythm [36,37]. Interestingly, recently a review article reported that targeting cellular metabolism can improve the efficacy of cancer therapy [38]. 
Table 1. GO analysis of 765 genes which TBI-induced alteration of expression were abolished or attenuated by MASM pretreatment. GO analysis was applied in terms of molecular function, cellular component and biological process $(p<0.05)$.

\begin{tabular}{ccccc}
\hline GOId & Name & Hits & Percent & Enrichment Test $p$ Value \\
\hline GO:0003674 & molecular_function & 550 & $3.7 \%$ & 1.0 \\
GO:0005215 & transporter activity & 65 & $6.07 \%$ & 0.0094 \\
GO:0045499 & chemorepellent activity & 2 & $40.0 \%$ & 0.0331 \\
GO:0005575 & cellular_component & 555 & $3.78 \%$ & 1.0 \\
GO:0044456 & synapse part & 24 & $6.72 \%$ & 0.0376 \\
GO:0008150 & biological_process & 518 & $3.76 \%$ & 1.0 \\
GO:0016265 & death & 75 & $5.69 \%$ & 0.0219 \\
GO:0032501 & multicellular organismal process & 275 & $5.1 \%$ & 0.0054 \\
GO:0032502 & developmental process & 204 & $5.02 \%$ & 0.0324 \\
GO:0040007 & growth & 36 & $6.04 \%$ & 0.0484 \\
GO:0040011 & locomotion & 54 & $6.41 \%$ & 0.0068 \\
GO:0048511 & rhythmic process & 26 & $11.02 \%$ & 0.0001 \\
GO:0050896 & response to stimulus & 236 & $4.96 \%$ & 0.0344 \\
GO:0051179 & localization & 174 & $5.12 \%$ & 0.0281 \\
\hline
\end{tabular}

Table 2. Pathway enrichment analysis of 765 genes which TBI-induced alteration of expression were abolished or attenuated by MASM pretreatment. KEGG pathway analysis indicated that these genes were mainly involved in a total of 21 pathways $(p<0.01)$.

\begin{tabular}{cccc}
\hline Name & Hits & Percent & Enrichment Test $p$ Value \\
\hline Olfactory transduction & 58 & $5.69 \%$ & 0.0 \\
Metabolic pathways & 38 & $3.15 \%$ & 0.0091 \\
Neuroactive ligand-receptor interaction & 18 & $5.54 \%$ & 0.0003 \\
Pathways in cancer & 16 & $4.79 \%$ & 0.0024 \\
MAPK signaling pathway & 13 & $4.73 \%$ & 0.0065 \\
Calcium signaling pathway & 13 & $6.81 \%$ & 0.0003 \\
Vascular smooth muscle contraction & 12 & $9.38 \%$ & 0.0 \\
Cytokine-cytokine receptor interaction & 12 & $4.88 \%$ & 0.0070 \\
Purine metabolism & 10 & $5.99 \%$ & 0.0035 \\
PPAR signaling pathway & 9 & $12.0 \%$ & 0.0001 \\
GnRH signaling pathway & 8 & $8.08 \%$ & 0.0016 \\
Gap junction & 8 & $9.2 \%$ & 0.0007 \\
Arachidonic acid metabolism & 7 & $9.46 \%$ & 0.0013 \\
Adipocytokine signaling pathway & 7 & $10.45 \%$ & 0.0008 \\
RNA degradation & 6 & $9.84 \%$ & 0.0024 \\
Type II diabetes mellitus & 5 & $9.43 \%$ & 0.0065 \\
Fatty acid metabolism & 5 & $11.11 \%$ & 0.0034 \\
Acute myeloid leukemia & 5 & $8.47 \%$ & 0.0098 \\
Galactose metabolism & 4 & $16.67 \%$ & 0.0024 \\
Circadian rhythm-mammal & 4 & $30.77 \%$ & 0.0003 \\
Bladder cancer & 4 & $10.81 \%$ & 0.0095 \\
\hline
\end{tabular}

For example, targeting metabolic enzymes, such as glucose transporters, fatty acid synthase and glutaminase can enhance the efficacy of common therapeutic agents or overcome resistance to chemotherapy or radiotherapy [38]. In addition, it has been reported that nicotinamide sensitizes tumors, at least in part, by modulating vascular smooth muscle contraction [39]. Matrine and its compounds have been widely used as adjuvant therapy in China to improve the 5-year survival rate and life quality of patients with cancer [14]. However, little is known about the mechanisms underlying the therapeutic effects of matrine. Table 2 showed that 38, 10, 7, 5 and 12 genes were involved in metabolic pathways, purine metabolism, arachidonic acid metabolism, fatty acid metabolism and vascular smooth muscle contraction, respectively. It is very likely that MASM/matrine improve the efficacy of cancer therapy, at least in part, by targeting these cellular metabolism and modulating vascular smooth muscle contraction, and this area is of great interest for our further studies. 
Since ionizing radiation induces simultaneous compensatory activation of multiple MAPK pathways [27], we focused on these pathways. These pathways play critical roles in controlling cell survival or death and repopulation effects following irradiation, in a cell-type-dependent manner [27]. The 13 genes presented in Table 3 were involved in multiple MAPK pathways including extracellular signal-regulated kinase (ERK), c-Jun N-terminal kinase (JNK), and p38 MAPK pathway.

Table 3. The 13 genes were involved in MAPK pathways. These genes that TBI-induced alteration of expression were abolished or attenuated by $30 \mathrm{mg} / \mathrm{kg}$ MASM pretreatment.

\begin{tabular}{|c|c|c|c|c|}
\hline GenBank & Symbol & Description & $\begin{array}{l}\text { Fold Change } \\
\text { TBI (6 Gy) }\end{array}$ & $\begin{array}{l}\text { Fold Change } \\
\text { MASM + TBI }\end{array}$ \\
\hline NM_130817 & Fgf3 & fibroblast growth factor 3 & 2.11 & 1.55 \\
\hline NM_012603 & Myc & myelocytomatosis oncogene & 3.41 & 2.54 \\
\hline NM_031598 & Pla2g2a/sPLA2 & phospholipase A2, group IIA & 5.65 & 2.12 \\
\hline NM_001008321 & Gadd45b & $\begin{array}{l}\text { growth arrest and } \\
\text { DNA-damage-inducible, } \beta\end{array}$ & 3.0 & 1.53 \\
\hline XM_001073032 & Map3k10 & $\begin{array}{l}\text { mitogen activated protein } \\
\text { kinase kinase kinase } 10\end{array}$ & 2.13 & 1.02 \\
\hline XM_344798 & RGD1306565/Ask1/Map3k5 & $\begin{array}{l}\text { similar to apoptosis } \\
\text { signal-regulating kinase } 1\end{array}$ & 0.42 & 0.76 \\
\hline NM_001033963 & Prkx/PKA & protein kinase, $\mathrm{X}$-linked & 1.58 & 1.34 \\
\hline NM_019294 & Cacna1e & $\begin{array}{l}\text { calcium channel, } \\
\text { voltage-dependent, R type, } \\
\text { alpha } 1 \mathrm{E} \text { subunit }\end{array}$ & 2.14 & 1.08 \\
\hline NM_053873 & Cacna1s/CACN & $\begin{array}{l}\text { calcium channel, } \\
\text { voltage-dependent, L type, } \\
\text { alpha } 1 S \text { subunit }\end{array}$ & 3.30 & 1.13 \\
\hline NM_021589 & Ntrk1 & $\begin{array}{l}\text { neurotrophic tyrosine kinase, } \\
\text { receptor, type } 1\end{array}$ & 0.29 & 0.61 \\
\hline NM_022702 & Taok2 & TAO kinase 2 & 1.66 & 1.0 \\
\hline NM_024403 & Atf4/CREB & activating transcription factor 4 & 1.54 & 1.13 \\
\hline NM_024388 & Nr4a1/Nur77 & $\begin{array}{l}\text { nuclear receptor subfamily } 4 \text {, } \\
\text { group A, member } 1\end{array}$ & 13.56 & 6.78 \\
\hline
\end{tabular}

This was consistent with previous reports that ionizing radiation activated all 3 MAPKs with different intensities and in a cell type-dependent context [27,40,41]. 11 of among gene expressions were evidently up-regulated by TBI and these up-regulations were abolished or attenuated by pretreatment with MASM. These TBI-induced genes include fibroblast growth factor 3 (Fgf3), myelocytomatosis oncogene (Myc), phospholipase A2, group IIA (Pla2g2a or sPLA2), growth arrest and DNA-damage-inducible, beta (Gadd45b), mitogen activated protein kinase kinase kinase 10 (Map3k10), protein kinase, $\mathrm{X}$-linked (Prkx), calcium channel, voltage-dependent, $\mathrm{R}$ type, alpha 1E subunit (Cacna1e), calcium channel, voltage-dependent, L type, alpha 1S subunit (Cacna1s), TAO kinase 2 (Taok2), activating transcription factor 4 (Atf4), nuclear receptor subfamily 4, group A, member 1 (Nr4a1). In contrast, the expressions of neurotrophic tyrosine kinase, receptor, type 1 (Ntrk1) and apoptosis signal-regulating kinase 1 (Ask1) were down-regulated by TBI and these down-regulations were abolished or attenuated by pretreatment with MASM. Interestingly, Nr4a1 was a growth factor-inducible member of the Nr4a1/Nur77 subfamily of the nuclear receptor superfamily of transcription factors. Nr4a1 was involved in determine whether cells undergo double-strand break (DSB) repair or apoptosis in response to irradiation [42]. A previous study reported that radiation up-regulated Nr4a1/Nur77 phosphorylation and expression [42]. In this study, our data indicated that Nr4a1 expression was evidently up-regulated by TBI and the TBI-induced increase was attenuated by pretreatment with MASM. In addition, activating transcription factor 4 (Atf4) was a member of the ATF/CREB (activating transcription factor/cyclic AMP response element binding protein) family of basic region-leucine zipper (bZip) transcription factors. Atf4 was induced by stress signals including endoplasmic reticulum stress, amino acid deprivation, anoxia/hypoxia and oxidative stress. 
Atf4 expression was regulated transcriptionally, translationally via the PERK pathway. Atf4 regulated the expression of genes involved in amino acid synthesis, oxidative stress, differentiation, metastasis and angiogenesis [43]. As described by the earlier reports [44,45], our data indicated that TBI increased the expression of Atf4/CREB. Myc was involved in a wide range of cellular processes including signal transduction, cell-cycle control, self-renewal, metabolism, maintenance of pluripotency, and control of cell fate decisions [46]. Here, our data indicated that the TBI-induced increase in Myc was attenuated by pretreatment with MASM. This was consistent with previous reports that irradiation significantly increased Myc $[47,48]$. Gadd45 proteins were implicated in stress signaling in response to environmental or physiological stressors, which resulted in either cell cycle arrest, DNA repair, cell survival and senescence, or apoptosis [49]. Consistent with the earlier reports [50,51], the expression of Gadd45b was up-regulated by radiation. Prkx was a member of an ancient family of cAMP-dependent serine/threonine kinases distinct from the classical PKA, PKB/Akt, PKC, SGK, and PKG families [52]. As described by the earlier reports [53,54], Prkx protein kinase was up-regulated by radiation. Ntrk1/Trk A was a member of the neurotrophic tyrosine kinase receptor (NTKR) family. Ntrk1 was a membrane-bound receptor that, upon neurotrophin binding, phosphorylates itself and members of the MAPK pathway. The presence of Ntrk1 leaded to cell differentiation and might play a role in specifying sensory neuron subtypes [55,56]. In UV-irradiated normal skin, there was a significant reduction in Trk A/Ntrk1 tyrosine kinase receptor immunostaining after UV-irradiation [57]. Albeit our data strongly support radiation-induced down-regulation of Ntrk1 [57], there are also reports on UV-induced up-regulation of both nerve growth factor NGF and its high-affinity receptor Ntrk1 [58]. cPLA2 was a member of the PLA2 enzyme superfamily, which included secretory PLA2 (sPLA2), cytosolic PLA2 (cPLA2), and other members. cPLA2, which activated AA hydrolysis, existed in three isoforms: $\alpha, \beta$, and $\gamma$. cPLA2- $\alpha$ was known to be a major component of the arachidonate-releasing signal transduction pathway [59,60]. Low level laser irradiation significantly inhibited phospholipase cPLA2- $\alpha$ mRNA expression, which was increased in response to mechanical stress [59]. Here, our data showed that TBI-induced increase in sPLA2 was attenuated by pretreatment with MASM. These data showed that MASM pretreatment could attenuate TBI-activated all 3 MAPKs (Table 3). In our previous study, MASM could inhibit the Akt pathway by suppressing the phosphorylation of Akt, glycogen synthase kinase $3 \beta$ (GSK3 $\beta$ ), and P70S6 kinase in cultured activated or TGF $\beta 1$-activated hepatic stellate cells [20]. In addition, our data showed that radiation-induced phosphorylation of P38 and JNK (c-Jun $\mathrm{NH}_{2}$-terminal kinase) was dose-dependently inhibited by pretreatment with MASM in murine macrophage RAW264.7 cells (unpublished data). Moreover, some agents were reported to provide the protective effects via the modulation of MAPKs pathway [61-64]. Taken together, these data indicated that the pretreatment of rats with MASM modulated lethal TBI-induced multiple MAPK pathways, suggesting that MASM might provide the protective effects mainly or partially through the modulation of MAPKs pathway. Therefore, MASM has the potential to be used as an effective therapeutic or radioprotective agent to minimize TBI-induced damages.

A number of studies demonstrated that the combined modality therapy involving radiation and MAPK pathway inhibitors was a promising strategy for improving the treatment of patients with cancer [40]. Preclinical and clinical evidence suggested that agents targeting aberrant tumor signals could effectively improve the therapeutic effect of ionizing radiation [24]. Here, this study suggested that MASM could offer radioprotection mainly or partially through the modulation of TBI-induced MAPKs pathway. Therefore, it is very likely that MASM is used in combination with radiotherapy to improve the efficacy of cancer therapy, and this area is of great interest for our further studies.

To validate the consistency of microarray analysis in the present study, we compared gene expression levels of selected genes between microarray and real-time PCR. We determined the mean value of expression of the selected genes in five independent rats from each exposure group. This was compared with those in pooled RNA from 5 non-irradiated rats. The qualitative changes in gene expression levels were consistent between these analyses (Figure 4). 


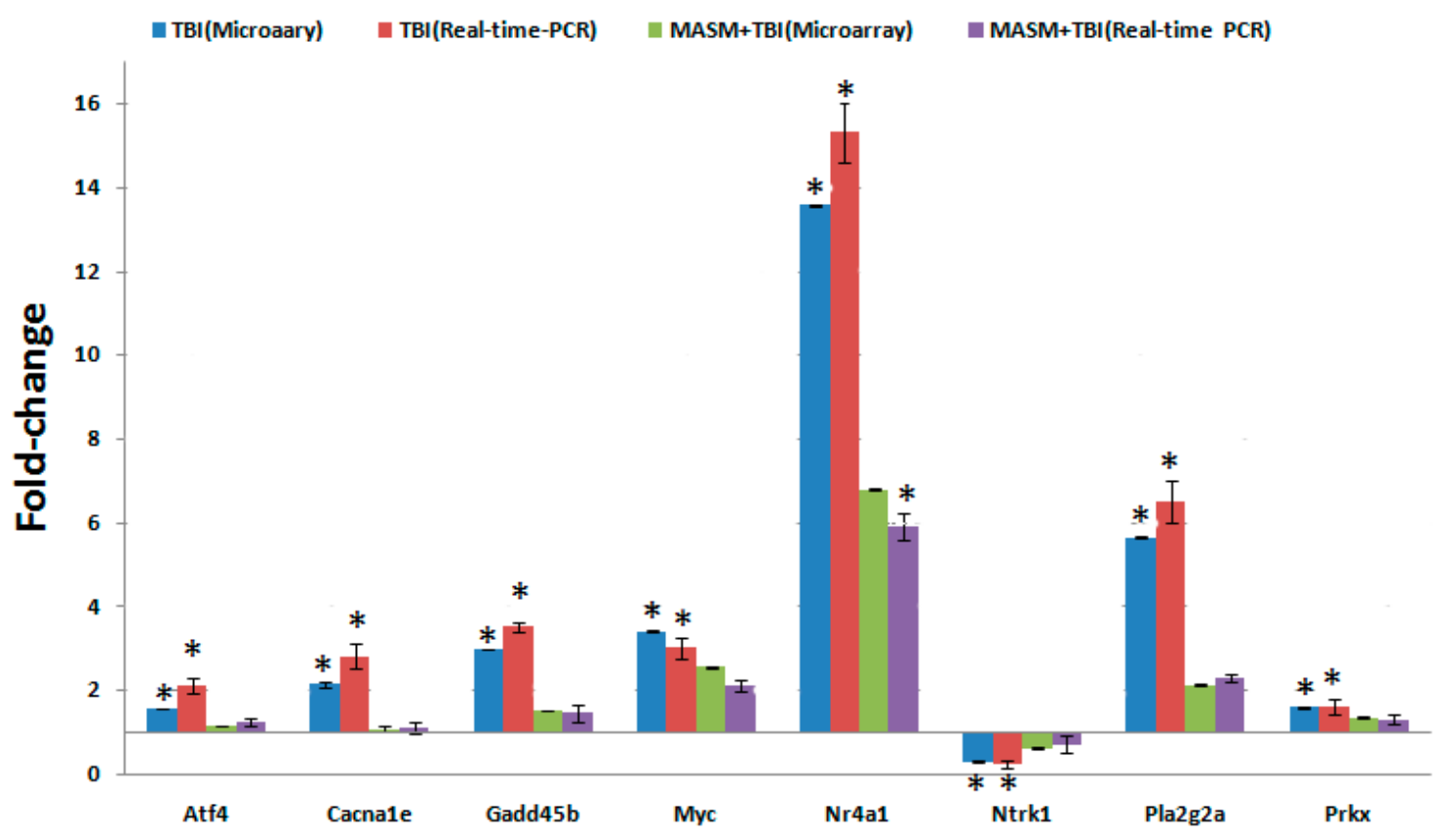

Figure 4. Quantitative real-time PCR confirmation of the microarray data. qRT-PCR was performed on 8 genes that TBI-induced alteration of expression was abolished or attenuated by $30 \mathrm{mg} / \mathrm{kg}$ MASM pretreatment. RNA samples of different groups ( $n=5$ per group) were prepared $24 \mathrm{~h}$ after exposure to 6 Gy TBI. Gene expression levels are shown as the mean normalized to the expression of the housekeeping gene beta-actin. Each sample was measured in triplicate. Columns, mean of three or four rats in the microarray experiment or mean of five rats in PCR; bars, SD. * indicates statistical significance compared to control (non-irradiation) by $t$-test, ${ }^{*} p<0.05$. Comparison of fold change produced by microarray with relative expression ratio obtained from real-time PCR, with good concordance.

\section{Materials and Methods}

\subsection{Chemicals}

The matrine derivative MASM [(6aS,10S,11aR,11bR,11cS)-10-methylamino-dodecahydro-3a,7adiazabenzo(de)anthracene-8-thione] (purity > 99\%) was synthesized via classical Michael addition and characterized as reported earlier [19].

\subsection{Animals}

Male Wistar rats (200-220 g) were purchased from SLAC Laboratory Animal Co. Ltd. (Shanghai, China) and divided randomly into several groups. Animals were kept under standard laboratory conditions of temperature, pressure and humidity. Food and water were sterilized by ${ }^{60} \mathrm{Co} \gamma$-irradiation and high pressure, respectively. All animal procedures were carried out in strict accordance with the recommendations in the Guide for the Care and Use of Laboratory Animals of the National Institutes of Health. The protocol was approved by the Committee on the Ethics of Animal Experiments of the Second Military Medical University (Shanghai, China). All surgery was performed under sodium pentobarbital anesthesia, and all efforts were made to minimize suffering.

\subsection{Radiation and Administration}

The animals were randomly assigned to one of the six following treatment groups (10-11 animals per group): normal control, MASM-High, radiation and MASM-High, Medium, Low dose (30, 10, $3 \mathrm{mg} / \mathrm{kg}$ body weight/day) + radiation. Different doses of MASM dissolved in double distilled water were administered intragastrically to the animals once each day for 3 consecutive days before or 
after irradiation. All animals, except the normal control group, were placed in specially designed, well-ventilated acrylic container and subjected to total-body irradiation (TBI). Radiation was delivered by the ${ }^{60} \mathrm{Co}$ source (Radiation facility, the Second Military Medical University, China). Radiation doses were $6,7 \mathrm{~Gy}$ at a rate $2 \mathrm{~Gy} / \mathrm{min}$. The animals were monitored daily for the development of symptoms of radiation sickness and mortality.

\subsection{Survival Assays}

Wistar rats ( $n=11$ rats /group) were administered MASM after or before exposure to TBI with 6 Gy or 7 Gy. We observed animals twice times daily for a period of 30 days to determine survival rates, and moribund animals were euthanized according to humane endpoints [65]. The clinical criteria of moribund is being in the state of dying with no expectation of recovery, where animals display a combination of the following: hunched back, lowered body temperature, impaired or slow motion, continuous shaking and inability to maintain sternal recumbency $[65,66]$. Moribund and surviving animals at the end of the study were subjected to euthanasia by the application of sodium pentobarbital anesthesia or $\mathrm{CO}_{2}$ followed by cervical dislocation. Survival of rats or mice from all the different groups was monitored from the day of onset of the experiment until the 30th day. The probabilities of the survival of all different groups were plotted as Kaplan-Meier survival curves until the 30th day. Significant differences in the survival curves among the different groups were evaluated using log rank test (Mantel-Cox test) for multiple groups.

\subsection{Sample Collection}

$24 \mathrm{~h}$ following irradiation, the rats were anesthetized and sacrificed by cervical dislocation. Thymus, spleen, liver, small intestine, testis, hippocampus, cortex and femoral were dissected out from each animal. The specimens of all groups were processed for ultrastructural examination. In addition, liver tissues of all groups were processed for the microarray experiment.

\subsection{Transmission Electron Microscopy}

Transmission electron microscopy was performed essentially as described previously [67]. Biopsy samples were cut and fixed in $2.5 \%$ glutaraldehyde in $0.1 \mathrm{M}$ sodium cacodylate, then post fixed with $1 \%$ osmium tetroxide. The specimens were dehydrated through a graded series of ethanol and then embedded in labeled capsules with freshly prepared resin and left to polymerize. Ultrathin sections were cut on an Ultracut UCT (Leica, Wetzlar, Germany) stained with uranyl acetate and lead citrate and examined by a 1200EX transmission electron microscope (JEOL, Peabody, MA, USA).

\subsection{Gene Expression Microarray and Data Analysis}

The microarray experiments were performed as described previously [68]. The $4 \times 44 \mathrm{~K}$ Whole Rat Genome Oligo Microarray (Agilent Technologies, Santa Clara, CA, USA) was hybridized with Cy3-labeled cRNA using a Gene Expression Hybridization Kit (Agilent Technologies) in a Hybridization Oven (Agilent Technologies), according to the manufacturer's instructions. Raw data were obtained by Feature Extraction software 10.7 (Agilent Technologies) and normalized by Quantile algorithm, Gene Spring Software 11.0 (Agilent Technologies). The microarray experiments were conducted at the National Engineering Center for Biochips in Shanghai, China, according to the procedures in the Agilent technical manual. After normalization, genes in the treatment groups with at least 1.5-fold change in expression were considered as up-regulated or down-regulated in comparison to non-treated groups (control). To determine significant proportions of differentially expressed genes within treated groups, the hypergeometric probability $p$ was calculated. $p<0.05$ was considered significant.

Microarray data analysis was performed using the SBC Analysis system, which is available on the website: http://www.ebioservice.com/. The username and password to access this website are 
available upon request. A general description of the SBC analysis system can be found on the website: http://www.ebioservice.com/sas.html. The microarray data generated in this study have been deposited in the Gene Expression Omnibus (GEO) database under the accession number GSE56263.

\subsection{Quantitative Real Time ( $q R T)-P C R$ Array Validation}

qRT-PCR was performed essentially as described previously[68]. In total, eight genes were chosen for RT-PCR validation. Because SYBR Green binding is not sequence specific, careful design and validation of each primer pair, as well as cautious manipulation of RNA were undertaken to ensure that only target gene sequence-specific, non-genomic products were amplified by real-time PCR. To achieve this, primers were designed to either span or flank introns by using the ProbeFinder version 2.49 software (Roche, West Sussex, UK). A dissociation curve analysis was performed at the end of the amplification process in order to verify the specificity of the PCR products. The same PCR products were also evaluated by agarose gel electrophoresis. Data are presented as mean \pm SD. The primers are as follows. Atf4 (NM_024403): forward, TCAGACACCGGCAAGGAG; reverse, GTGGCCAAAAGCTCATCTG. Cacna1e (NM_019294): forward, GAAATTATCCTGACAGACAGCAAG; reverse, AGCTTTATGAGCCGTGCAG. Gadd45b (NM_001008321): forward, CTGCCTCCTGGTCACGAA; reverse, TTGCCTCTGCTCTCTTCACA. Мус (NM_012603): forward, GAATTTTTGTCTATTTGGGGACA; reverse, GCATCGTCGTGACTGTCG. Nr4a1 (NM_024388): forward, TGTTGATGTTCCTGCCTTTG; reverse, GGAGGCCATGTCGATCAG. Ntrk1 (NM_021589): forward, CAGCTTCTGGCTGTGGCTA; reverse, AAGTGCAGGCTGGCTAGGTA. Pla2g2a (NM_031598): forward, CTGACCTACAAGTTCTCCTACCG; reverse, TTATCGCACTGGCACAGC. Prkx (NM_001033963): forward, GCCTGGGCAACATGAAGA; reverse, TCCACACCTCGGAACCAC. $\beta$-Actin (NM_031144): forward, CCCGCGAGTACAACCTTCT; reverse, CGTCATCCATGGCGAACT.

\subsection{Statistical Analysis}

Data were presented as mean \pm SD. One-way analysis of variance (ANOVA) followed by the Dunnett's test was used to examine differences among the different treatment groups. Differences were considered significant when $p<0.05$ or $p<0.01$.

Supplementary Materials: The following are available online at: http:/ /www.mdpi.com/1420-3049/21/5/649/s1 Supplementary File 1 lists 3912 differentially expressed transcripts (probesets) by using one-way analysis of variance $(p<0.01)$. Supplementary File 2 lists 2920 differentially expressed probes $(\mathrm{FC} \geqslant 1.5, p<0.05)$ were selected by comparison between radiation and wild-type (control) samples. Supplementary File 3 lists 765 genes for which radiation-induced alteration of expression were abolished or attenuated by MASM.

Acknowledgments: This work was supported by the National Major Projects of China (No. 2010ZXJ0900X-005 and 2011VSJ09201-012) and the National Natural Science Foundation of China (No. 81570557).

Author Contributions: Jianzhong Li was involved in all experiments, experimental design and bioinformatics analyses, drafted the manuscript. Jing Xu and Weiheng Xu performed Real RT-PCR. Lei Qiu, Zhenlin Hu and Bin Lu assisted in bioinformatics analyses and uploaded data to Gene Expression Omnibus. Yiming Lu and Zhiyong Chu performed transmission electron microscopy. Junping Zhang and Yifeng Chai co-drafted the manuscript, made revisions critically for important intellectual content. All authors read and approved the final manuscript.

Conflicts of Interest: The authors declare no conflict of interest.

\section{References}

1. Moores, B.M.; Regulla, D. A review of the scientific basis for radiation protection of the patient. Radiat. Prot. Dosim. 2011, 147, 22-29. [CrossRef] [PubMed]

2. Hamada, N. Recent insights into the biological action of heavy-ion radiation. J. Radiat. Res. 2009, 50, 1-9. [CrossRef] [PubMed]

3. Bortfeld, T.; Jeraj, R. The physical basis and future of radiation therapy. Br. J. Radiol. 2011, 84, 485-498. [CrossRef] [PubMed] 
4. Gandhi, N.M.; Nair, C.K. Radiation protection by diethyldithiocarbamate: Protection of membrane and DNA in vitro and in vivo against gamma-radiation. J. Radiat. Res. 2004, 45, 175-180. [CrossRef] [PubMed]

5. Nair, C.K.; Parida, D.K.; Nomura, T. Radioprotectors in radiotherapy. J. Radiat. Res. 2001, 42, $21-37$. [CrossRef] [PubMed]

6. Hosseinimehr, S.J. Trends in the development of radioprotective agents. Drug Discov. Today 2007, 12, 794-805. [CrossRef] [PubMed]

7. Wang, Z.; Zhang, J.; Wang, Y.; Xing, R.; Yi, C.; Zhu, H.; Chen, X.; Guo, J.; Guo, W.; Li, W.; et al. Matrine, a novel autophagy inhibitor, blocks trafficking and the proteolytic activation of lysosomal proteases. Carcinogenesis 2013, 34, 128-138. [CrossRef] [PubMed]

8. Zhang, S.; Zhang, Y.; Zhuang, Y.; Wang, J.; Ye, J.; Zhang, S.; Wu, J.; Yu, K.; Han, Y. Matrine induces apoptosis in human acute myeloid leukemia cells via the mitochondrial pathway and Akt inactivation. PLoS ONE 2012, 7, e46853. [CrossRef] [PubMed]

9. Li, X.; Chu, W.; Liu, J.; Xue, X.; Lu, Y.; Shan, H.; Yang, B. Antiarrhythmic properties of long-term treatment with matrine in arrhythmic rat induced by coronary ligation. Biol. Pharm. Bull. 2009, 32, 1521-1526. [CrossRef] [PubMed]

10. Liu, J.Y.; Hu, J.H.; Zhu, Q.G.; Li, F.Q.; Wang, J.; Sun, H.J. Effect of matrine on the expression of substance $\mathrm{P}$ receptor and inflammatory cytokines production in human skin keratinocytes and fibroblasts. Int. Immunopharmacol. 2007, 7, 816-823. [CrossRef] [PubMed]

11. Cheng, H.; Xia, B.; Zhang, L.; Zhou, F.; Zhang, Y.X.; Ye, M.; Hu, Z.G.; Li, J.; Li, J.; Wang, Z.L.; et al. Matrine improves 2,4,6-trinitrobenzene sulfonic acid-induced colitis in mice. Pharmacol. Res. 2006, 53, 202-208. [CrossRef] [PubMed]

12. Long, Y.; Lin, X.T.; Zeng, K.L.; Zhang, L. Efficacy of intramuscular matrine in the treatment of chronic hepatitis B. Hepatobiliary Pancreat Dis. Int. 2004, 3, 69-72. [PubMed]

13. Zhang, J.P.; Zhang, M.; Zhou, J.P.; Liu, F.T.; Zhou, B.; Xie, W.F.; Guo, C. Antifibrotic effects of matrine on in vitro and in vivo models of liver fibrosis in rats. Acta Pharmacol. Sin. 2001, 22, 183-186. [PubMed]

14. Sun, M.; Cao, H.; Sun, L.; Dong, S.; Bian, Y.; Han, J.; Zhang, L.; Ren, S.; Hu, Y.; Liu, C.; et al. Antitumor activities of kushen: Literature review. Evid. Based Complement. Altern. Med. 2012, 2012, 373219. [CrossRef] [PubMed]

15. Fan, C.X.; Lin, C.L.; Liang, L.; Zhao, Y.Y.; Liu, J.; Cui, J.; Yang, Q.M.; Wang, Y.L.; Zhang, A.R. Enhancing effect of compound Kusheng injection in combination with chemotherapy for patients with advanced non-small cell lung cancer. Chin. J. Oncol. 2010, 32, 294-297.

16. Chen, J.; Mei, Q.; Xu, Y.C.; Du, J.; Wei, Y.; Xu, Z.M. Effects of Matrine Injection on T-lymphocyte subsets of patients with malignant tumor after gamma knife radiosurgery. J. Chin. Integr. Med. 2006, 4, 78-79. [CrossRef]

17. Lao, Y. Clinical study on effect of matrine injection to protect the liver function for patients with primary hepatic carcinoma after trans-artery chemo-embolization (TAE). J. Chin. Med. Mater. 2005, 28, 637-638.

18. Lao, Y. Clinical study of matrine injection on preventing liver function damage of anti-tumor drugs during chemotherapy of breast cancer. J. Chin. Med. Mater. 2005, 28, 735-737.

19. Hu, H.; Wang, S.; Zhang, C.; Wang, L.; Ding, L.; Zhang, J.; Wu, Q. Synthesis and in vitro inhibitory activity of matrine derivatives towards pro-inflammatory cytokines. Bioorg. Med. Chem. Lett. 2010, 20, 7537-7539. [CrossRef] [PubMed]

20. Xu, W.H.; Hu, H.G.; Tian, Y.; Wang, S.Z.; Li, J.; Li, J.Z.; Deng, X.; Qian, H.; Qiu, L.; Hu, Z.L.; et al. Bioactive compound reveals a novel function for ribosomal protein S5 in hepatic stellate cell activation and hepatic fibrosis. Hepatology 2014, 60, 648-660. [CrossRef] [PubMed]

21. Stryker, J.A. Science to practice: Why is the liver a radiosensitive organ? Radiology 2007, 242, 1-2. [CrossRef] [PubMed]

22. Julius, D.; Nathans, J. Signaling by sensory receptors. Cold Spring Harb. Perspect. Biol. 2012, 4, a005991. [CrossRef] [PubMed]

23. Herok, R.; Konopacka, M.; Polanska, J.; Swierniak, A.; Rogolinski, J.; Jaksik, R.; Hancock, R.; Rzeszowska-Wolny, J. Bystander effects induced by medium from irradiated cells: Similar transcriptome responses in irradiated and bystander K562 cells. Int. J. Radiat. Oncol. Biol. Phys. 2010, 77, 244-252. [CrossRef] [PubMed] 
24. Ding, M.; Zhang, E.; He, R.; Wang, X. Newly developed strategies for improving sensitivity to radiation by targeting signal pathways in cancer therapy. Cancer Sci. 2013, 104, 1401-1410. [CrossRef] [PubMed]

25. Naziroglu, M.; Tokat, S.; Demirci, S. Role of melatonin on electromagnetic radiation-induced oxidative stress and $\mathrm{Ca}^{2+}$ signaling molecular pathways in breast cancer. J. Recept. Signal Transduct. Res. 2012, 32, 290-297. [CrossRef] [PubMed]

26. Gupta, S.; Ahmed, M.M. A global perspective of radiation-induced signal transduction pathways in cancer therapeutics. Indian J. Exp. Biol. 2004, 42, 1153-1176. [PubMed]

27. Dent, P.; Yacoub, A.; Fisher, P.B.; Hagan, M.P.; Grant, S. MAPK pathways in radiation responses. Oncogene 2003, 22, 5885-5896. [CrossRef] [PubMed]

28. Linard, C.; Gremy, O.; Benderitter, M. Reduction of peroxisome proliferation-activated receptor gamma expression by gamma-irradiation as a mechanism contributing to inflammatory response in rat colon: Modulation by the 5-aminosalicylic acid agonist. J. Pharmacol. Exp. Ther. 2008, 324, 911-920. [CrossRef] [PubMed]

29. Roth, C.; Schmidberger, H.; Lakomek, M.; Witt, O.; Wuttke, W.; Jarry, H. Reduction of gamma-aminobutyric acid-ergic neurotransmission as a putative mechanism of radiation induced activation of the gonadotropin releasing-hormone-pulse generator leading to precocious puberty in female rats. Neurosci. Lett. 2001, 297, 45-48. [CrossRef]

30. Olme, C.H.; Finnon, R.; Brown, N.; Kabacik, S.; Bouffler, S.D.; Badie, C. Live cell detection of chromosome 2 deletion and Sfpi1/PU1 loss in radiation-induced mouse acute myeloid leukaemia. Leuk. Res. 2013, 37, 1374-1382. [CrossRef] [PubMed]

31. Weil, M.M.; Bedford, J.S.; Bielefeldt-Ohmann, H.; Ray, F.A.; Genik, P.C.; Ehrhart, E.J.; Fallgren, C.M.; Hailu, F.; Battaglia, C.L.; Charles, B.; et al. Incidence of acute myeloid leukemia and hepatocellular carcinoma in mice irradiated with $1 \mathrm{GeV} /$ nucleon ${ }^{56} \mathrm{Fe}$ ions. Radiat. Res. 2009, 172, 213-219. [CrossRef] [PubMed]

32. Soloviev, A.I.; Tishkin, S.M.; Zelensky, S.N.; Ivanova, I.V.; Kizub, I.V.; Pavlova, A.A.; Moreland, R.S. Ionizing radiation alters myofilament calcium sensitivity in vascular smooth muscle: Potential role of protein kinase C. Am. J. Physiol. Regul. Integr. Comp. Physiol. 2005, 289, R755-R762. [CrossRef] [PubMed]

33. Zhou, H.; Ivanov, V.N.; Gillespie, J.; Geard, C.R.; Amundson, S.A.; Brenner, D.J.; Yu, Z.; Lieberman, H.B.; Hei, T.K. Mechanism of radiation-induced bystander effect: Role of the cyclooxygenase-2 signaling pathway. Proc. Natl. Acad. Sci. USA 2005, 102, 14641-14646. [CrossRef] [PubMed]

34. Walsh, L.; Schneider, U. A method for determining weights for excess relative risk and excess absolute risk when applied in the calculation of lifetime risk of cancer from radiation exposure. Radiat. Environ. Biophys. 2013, 52, 135-145. [CrossRef] [PubMed]

35. Little, J.B. Radiation carcinogenesis. Carcinogenesis 2000, 21, 397-404. [CrossRef] [PubMed]

36. Gauger, M.A.; Sancar, A. Cryptochrome, circadian cycle, cell cycle checkpoints, and cancer. Cancer Res. 2005, 65, 6828-6834. [CrossRef] [PubMed]

37. Rubin, N.H. Influence of the circadian rhythm in cell division on radiation-induced mitotic delay in vivo. Radiat. Res. 1982, 89, 65-76. [CrossRef] [PubMed]

38. Zhao, Y.; Butler, E.B.; Tan, M. Targeting cellular metabolism to improve cancer therapeutics. Cell Death Dis. 2013, 4, e532. [CrossRef] [PubMed]

39. Ruddock, M.W.; Hirst, D.G. Nicotinamide relaxes vascular smooth muscle by inhibiting myosin light chain kinase-dependent signaling pathways: Implications for anticancer efficacy. Oncol. Res. 2004, 14, 483-489. [PubMed]

40. Munshi, A.; Ramesh, R. Mitogen-activated protein kinases and their role in radiation response. Genes Cancer 2013, 4, 401-408. [CrossRef] [PubMed]

41. Schmidt-Ullrich, R.K.; Dent, P.; Grant, S.; Mikkelsen, R.B.; Valerie, K. Signal transduction and cellular radiation responses. Radiat. Res. 2000, 153, 245-257. [CrossRef]

42. Zhao, B.X.; Chen, H.Z.; Du, X.D.; Luo, J.; He, J.P.; Wang, R.H.; Wang, Y.; Wu, R.; Hou, R.R.; Hong, M.; et al . Orphan receptor TR3 enhances p53 transactivation and represses DNA double-strand break repair in hepatoma cells under ionizing radiation. Mol. Endocrinol. 2011, 25, 1337-1350. [CrossRef] [PubMed]

43. Ameri, K.; Harris, A.L. Activating transcription factor 4. Int. J. Biochem. Cell Biol. 2008, 40, 14-21. [CrossRef] [PubMed]

44. Lee, W.H.; Sonntag, W.E.; Mitschelen, M.; Yan, H.; Lee, Y.W. Irradiation induces regionally specific alterations in pro-inflammatory environments in rat brain. Int. J. Radiat. Biol. 2010, 86, 132-144. [CrossRef] [PubMed] 
45. Cataldi, A.; Di Giacomo, V.; Rapino, M.; Zara, S.; Rana, R.A. Ionizing radiation induces apoptotic signal through protein kinase Cdelta (delta) and survival signal through Akt and cyclic-nucleotide response element-binding protein (CREB) in Jurkat T cells. Biol. Bull. 2009, 217, 202-212. [PubMed]

46. Chappell, J.; Dalton, S. Roles for MYC in the Establishment and Maintenance of Pluripotency. Cold Spring Harb. Perspect. Med. 2013, 3, a014381. [CrossRef] [PubMed]

47. Borovitskaya, A.E.; Evtushenko, V.I.; Sabol, S.L. Gamma-radiation-induced cell death in the fetal rat brain possesses molecular characteristics of apoptosis and is associated with specific messenger RNA elevations. Brain Res. Mol. Brain Res. 1996, 35, 19-30. [CrossRef]

48. Wilson, R.E.; Taylor, S.L.; Atherton, G.T.; Johnston, D.; Waters, C.M.; Norton, J.D. Early response gene signalling cascades activated by ionising radiation in primary human B cells. Oncogene 1993, 8, 3229-3237. [PubMed]

49. Liebermann, D.A.; Hoffman, B. Gadd45 in the response of hematopoietic cells to genotoxic stress. Blood Cells Mol. Dis. 2007, 39, 329-335. [CrossRef] [PubMed]

50. Grace, M.B.; McLeland, C.B.; Blakely, W.F. Real-time quantitative RT-PCR assay of GADD45 gene expression changes as a biomarker for radiation biodosimetry. Int. J. Radiat. Biol. 2002, 78, 1011-1021. [CrossRef] [PubMed]

51. Daino, K.; Ichimura, S.; Nenoi, M. Early induction of CDKN1A (p21) and GADD45 mRNA by a low dose of ionizing radiation is due to their dose-dependent post-transcriptional regulation. Radiat. Res. 2002, 157, 478-482. [CrossRef]

52. Li, X.; Li, H.P.; Amsler, K.; Hyink, D.; Wilson, P.D.; Burrow, C.R. PRKX, a phylogenetically and functionally distinct cAMP-dependent protein kinase, activates renal epithelial cell migration and morphogenesis. Proc. Natl. Acad. Sci. USA 2002, 99, 9260-9265. [CrossRef] [PubMed]

53. Chin, C.; Bae, J.H.; Kim, M.J.; Hwang, J.Y.; Kim, S.J.; Yoon, M.S.; Lee, M.K.; Kim, D.W.; Chung, B.S.; Kang, C.D.; et al. Radiosensitization by targeting radioresistance-related genes with protein kinase A inhibitor in radioresistant cancer cells. Exp. Mol. Med. 2005, 37, 608-618. [CrossRef] [PubMed]

54. Fujino, M.; Ohnishi, K.; Asahi, M.; Wang, X.; Takahashi, A.; Ohnishi, T. Effects of protein kinase inhibitors on radiation-induced WAF1 accumulation in human cultured melanoma cells. Br. J. Dermatol. 1999, 141, 652-657. [CrossRef] [PubMed]

55. Pearce, L.R.; Komander, D.; Alessi, D.R. The nuts and bolts of AGC protein kinases. Nat. Rev. Mol. Cell Biol. 2010, 11, 9-22. [CrossRef] [PubMed]

56. Murakami, M.; Elfenbein, A.; Simons, M. Non-canonical fibroblast growth factor signalling in angiogenesis. Cardiovasc. Res. 2008, 78, 223-231. [CrossRef] [PubMed]

57. Bull, H.A.; Leslie, T.A.; Chopra, S.; Dowd, P.M. Expression of nerve growth factor receptors in cutaneous inflammation. Br. J. Dermatol. 1998, 139, 776-783. [CrossRef] [PubMed]

58. Weinkauf, B.; Rukwied, R.; Quiding, H.; Dahllund, L.; Johansson, P.; Schmelz, M. Local gene expression changes after UV-irradiation of human skin. PLoS ONE 2012, 7, e39411. [CrossRef] [PubMed]

59. Mayahara, K.; Yamaguchi, A.; Sakaguchi, M.; Igarashi, Y.; Shimizu, N. Effect of Ga-Al-As laser irradiation on COX-2 and cPLA2-alpha expression in compressed human periodontal ligament cells. Lasers Surg. Med. 2010, 42, 489-493. [CrossRef] [PubMed]

60. Degousee, N.; Ghomashchi, F.; Stefanski, E.; Singer, A.; Smart, B.P.; Borregaard, N.; Reithmeier, R.; Lindsay, T.F.; Lichtenberger, C.; Reinisch, W.; et al. Groups IV, V, and X phospholipases A2s in human neutrophils: Role in eicosanoid production and gram-negative bacterial phospholipid hydrolysis. J. Biol. Chem. 2002, 277, 5061-5073. [CrossRef] [PubMed]

61. Yu, D.H.; Ma, C.H.; Yue, Z.Q.; Yao, X.; Mao, C.M. Protective Effect of Naringenin against Lipopolysaccharide-Induced Injury in Normal Human Bronchial Epithelium via Suppression of MAPK Signaling. Inflammation 2015, 38, 195-204. [CrossRef] [PubMed]

62. Martinel Lamas, D.J.; Carabajal, E.; Prestifilippo, J.P.; Rossi, L.; Elverdin, J.C.; Merani, S.; Bergoc, R.M.; Rivera, E.S.; Medina, V.A. Protection of radiation-induced damage to the hematopoietic system, small intestine and salivary glands in rats by JNJ7777120 compound, a histamine H4 ligand. PLoS ONE 2013, 8, e69106.

63. Che, J.; Lu, Y.W.; Sun, K.K.; Feng, C.; Dong, A.J.; Jiao, Y. Overexpression of TOB1 confers radioprotection to bronchial epithelial cells through the MAPK/ERK pathway. Oncol. Rep. 2013, 30, 637-642. [PubMed] 
64. Arany, P.R.; Flanders, K.C.; DeGraff, W.; Cook, J.; Mitchell, J.B.; Roberts, A.B. Absence of Smad3 confers radioprotection through modulation of ERK-MAPK in primary dermal fibroblasts. J. Dermatol. Sci. 2007, 48, 35-42. [CrossRef] [PubMed]

65. Fukumoto, R.; Burns, T.M.; Kiang, J.G. Ciprofloxacin enhances stress erythropoiesis in spleen and increases survival after whole-body irradiation combined with skin-wound trauma. PLoS ONE 2014, 9, e90448. [CrossRef] [PubMed]

66. Toth, L.A. Defining the moribund condition as an experimental endpoint for animal research. ILAR J. Natl. Res. Counc. Inst. Lab. Anim. Resour. 2000, 41, 72-79. [CrossRef]

67. Hussein, M.R.; Abu-Dief, E.E.; Abou El-Ghait, A.T.; Adly, M.A.; Abdelraheem, M.H. Morphological evaluation of the radioprotective effects of melatonin against X-ray-induced early and acute testis damage in Albino rats: An animal model. Int. J. Exp. Pathol. 2006, 87, 237-250. [CrossRef] [PubMed]

68. Li, J.; Chen, X.; Gong, X.; Liu, Y.; Feng, H.; Qiu, L.; Hu, Z.; Zhang, J. A transcript profiling approach reveals the zinc finger transcription factor ZNF191 is a pleiotropic factor. BMC Genom. 2009, 10, 241. [CrossRef] [PubMed]

Sample Availability: Samples of the compounds are not available from the authors.

(c) 2016 by the authors; licensee MDPI, Basel, Switzerland. This article is an open access article distributed under the terms and conditions of the Creative Commons Attribution (CC-BY) license (http://creativecommons.org/licenses/by/4.0/). 